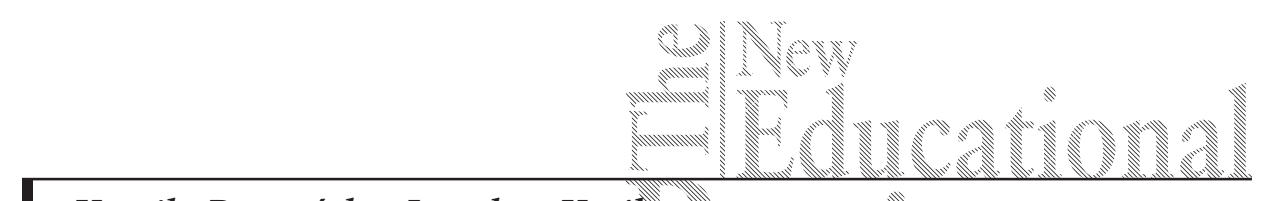

Kamila Burzyńska, Jarosław Krajka

Poland

\title{
Learning Strategies in the Digital Age - Towards a New Taxonomy for The Language Classroom
}

DOI: 10.15804/tner.2015.41.3.06

\begin{abstract}
The main objective of the presented study was to propose a new taxonomy of learning strategies for the digital age. The revised taxonomy of Oxford's SILL (1990) was implemented in a nationwide questionnaire to display the picture of strategy use, investigate relationships between particular strategy types and elicit learners' preferences on strategy instruction. The data was processed statistically with SPSS 20 package.

Results confirm high reliability of SI-LLE, indicate relatively strong relationships between particular strategy groups, where higher education institution, year of studies and teaching experience have a statistically significant effect of similar strength on strategy awareness.
\end{abstract}

Keywords: learning strategies, strategy training, metacognitive strategies, memory strategies, social strategies, affective strategies

\section{Introduction}

Together with an increased emphasis on learner-centred instruction, the issue of strategy training gains paramount importance. The focus of teaching, thus, should not be solely the transfer of subject-matter knowledge but also equipping learners with skills necessary for self-reliant acquisition of knowledge and skills in a particular domain.

Contemporary learning environments call for a redefinition of a traditional strategy framework. The provision of new technologies, ubiquitous online pres- 
ence, social networking, Web 2.0 personalized applications, mobile technologies, have brought about a need to reformulate our understanding of what particular steps or operations can facilitate the learning process.

\section{Research Problem}

The aim of the presented paper is to verify empirically the new strategy taxonomy, together with specific strategy statements put into a diagnostic questionnaire. Most importantly, the relationships between particular strategy groups and the effect of socio-demographic variables and learning experiences on the awareness of and willingness to participate in strategy training was the focus of research.

\section{Research Focus}

There is a significant body of research into the topic of strategies and their use in the language learning process. The studies stress the fact that a great number of students apply specific strategies when it comes to vocabulary learning, even if they are not fully aware of their own actions (Schmitt, 1997). They also reveal a necessity to adapt strategies to each learner's needs since different strategies contribute differently to learners' success (Nassaji, 2003).

Undoubtedly, being able to boast a great number of "battle plans for learning" (Brown, 1987) seems an advantage. As Chamot points out (2004), students who have a vast array of learning strategies at their disposal are the ones who can achieve a greater success in learning. $\mathrm{Gu}$ (2003) emphasizes the role of conscious strategy use while gaining considerable academic achievement.

As regards contemporary multimodal language learning environments, $\mathrm{Li}$ (2009) proves that technology-enhanced scaffoldings are of help in students' reading-based vocabulary acquisition. Chen, Zhang and Liu (2013) claim that listening strategy use can be affected by motivation, anxiety and leaning styles and that there are ways of strategy instruction which may enhance students' listening comprehension due to various features of Web-based CALL.

There are, however, numerous challenges which encompass learners' underuse and misuse of learning strategies. Ranalli (2010) mentions "the shortage of training materials, the lack of teacher expertise and ingrained habits or even resistance on the part of the learner" as problems referring to the integration of learner training 
in the use of strategies. As stressed by Hubbard (2004), effective computer-based strategy training appears, nonetheless, an area open to further research.

The existing strategy taxonomies (Wenden, 1983, O'Malley and Chamot, 1985 and Oxford, 1990) generally distinguish two areas of focus: strategies involved in language processing and strategies supporting learning the language. O’Malley and Chamot as well as Oxford additionally include social and affective strategies, emphasizing the crucial role that the ways to interact with others successfully and to take care of one's well-being play in the learning process. Even though Bull (1997) offers a list of potential strategies used in CALL contexts, they are only within the cognitive and metacognitive domains.

Very few studies attempted at elaborating the list of strategies that could be used in technology-enhanced language learning. The potential empirical value of the presented study, therefore, lies in launching a revised taxonomy of strategies in digital environments.

\section{$\underline{\text { Research Methodology }}$}

\section{General Background of Research}

The presented study was inspired by the authors' previous research (Burzyńska, Krajka, 2014), which aimed at investigating students' strategy use in CALL environments. The triangular research design was used then to establish greater validity in the studies. Initially, the participants were involved in a number of activities where technology use constituted an integral part of the lessons' content in a series of subsequent meetings. The three English for Academic Purposes Quests (Burzyńska, 2012) the students participated in ended up in the students' projections of their web search results in a form of essays. The activity format mentioned above got the students to test different possibilities the digital environments provide and consequently apply various strategies which may have extended the repertoire of strategies one would use in traditional learning environments. Meanwhile, the students' attempts at dealing with particular steps of the web-based tasks were observed and thorough notes during the observations were taken. Apart from these, informal interviews with the participants were conducted on a regular basis, after each EAP Quest they participated in. The subjects were given opportunities to share they experience when handling particular stages of the EAP quests and encountering learning-related problems. The data gathered during the aforementioned observations as well as interviews triggered redefinition of the existing strategy taxonomies for language learning. One of 
the most renowned classifications, i.e., Oxford's strategy taxonomy (1990), was analyzed and subsequently modified to include the strategy types gathered during the research. The final part of the research was aimed at testing the applicability of the modified taxonomy, revealing the frequency of certain strategies use and checking upon the learners' attitudes towards the Web-mediated instruction. The classification was put into practice in a survey as a pilot study to verify the reliability and validity of the research instrument. In the presented study, the improved version of this diagnostic questionnaire, which is labelled SI-LLE (Strategy Inventory for Language Learning Environments) following Oxford's (1990) SILL (Strategy Inventory for Language Learning), was tested in a larger sample with the hope to provide more generalizable results and draw more valid conclusions.

\section{Research Sample}

The study was conducted in a nationwide sample of 188 foreign language student teachers in Poland. The cluster sampling method was employed (Cohen, Manion, Morrison, 2011), in which locations of participants are selected on a purposive basis, but then, within the clusters, randomized subject selection takes place. Due to the employment of this technique, even though the sample in itself was not representative, some effort at its randomization was made to increase the validity of the findings.

The respondents were the students of Teacher Training College in Radom (53), the University of Humanities and Technologies in Radom (40), Warsaw University (50), and Maria Curie Skłodowska University in Lublin (15). They were the students of English (138) and German Language Studies (50). As regards their age, the participants in the survey were mainly $19-25$ (96\%), with only $1.5 \%$ being in the age range $26-30$ and $2.1 \%$ above 30 years of age, $39 \%$ male and $61 \%$ female. Almost a half of the sample were in their first year of university education (47\%), with $37 \%$ in the second and $16 \%$ in the third year. Even though they were relatively low in their college/university development, a quarter of the participants reported having some teaching experience (of different sort).

\section{Instrument and Procedures}

The revised taxonomy of learning strategies was put into practice in a diagnostic questionnaire - SI-LLE (Strategy Inventory for Language Learning Environments). The instrument consisted of six groups of Likert scale questions (ranging from 1 - never or almost never true of me to 5 - always or almost always true of me) eliciting the frequency of the use of particular operations. The statements 
were collected in the following strategy scales: Learning Strategies (LS), Memory Strategies (MEMS), Compensation Strategies (CS), Metacognitive Strategies (MS), Social Strategies (SS) and Affective Strategies (AS). The final statement in each scale was open-ended, for the respondents to name their own strategies. The basic socio-demographic data (age, sex, type of teacher training institution and year of studies) was collected at the beginning of the questionnaire.

The SI-LLE tool was pre-piloted with a small sample of participants to make sure its wording is fully comprehensible and precise. The findings were supplemented with material obtained during the semi-structured interviews conducted with the students. In addition, it seemed reasonable to interview the instructors, too. Consultations over the practicality, clarity and wording in the diagnostic questionnaire resulted in reformulating certain statements, relabeling strategy types and cutting some descriptions short. In consequence, the data triangulation influenced the present shape of the instrument so as to make it more comprehensible and user-friendly.

In the current study, within the cluster sampling approach (Cohen, Manion, Morrison, 2011) a list of institutions training foreign language teachers in the central region of Poland was created. Afterwards, key contacts in the clusters were established, to administer the questionnaire in a face-to-face mode to ensure a higher response rate and greater validity of responses. The contacts were either sent the paper questionnaire or a link to its online version and were free to randomize the selection of participating student teachers in their institutions.

\section{Data Analysis}

In the first step of data analysis descriptive statistics were obtained, such as distribution of scores on particular strategies, the values of strategy indices (computation of positive scores on the Likert scale for all the strategies in a given group, with negative scores subtracted from the total number), etc. Normality of the distribution of strategy index scores was assessed with Kolmogorov-Smirnov's and Shapiro-Wilk's tests, to decide which further procedures should be applied. The final part of the initial data processing was assessing the reliability of the questionnaire tool, with a special focus on internal consistency of particular strategy scales. For that purpose, Cronbach's alpha was computed for Likert-scale responses within particular strategy groups. In the second step of data analysis, the data set was tested for relationships with the inferential statistics procedures. 


\section{Research Results}

\section{Descriptive Statistics}

Among cognitive strategies, listening to podcasts, songs and other audio materials were reported most frequently. Reading texts in English on the Internet was in the second position (with the median of 3.75). Others that followed were: watching videos (3.57), using social networking to practise English (3.56) and reading feedback information after an activity if there is one given (3.40). The students pointed at making one's own materials (videos/presentations) in English and uploading them onto the Internet as the least frequently used strategy.

When it comes to compensation strategies, the learners reported fairly frequently reading a text more than once when having problems with understanding (4.26), trying to understand audio/video materials by looking into the general context (4.18), using an e-dictionary (4.18) or an on-line translator (3.79). Collecting questions and asking the teacher for help (2.57) and contacting friends via a social network/e-mail and asking for help (2.89) received the lowest ranks.

As regards memory strategies, reading materials at the computer (3.73), using a highlighting (underlining/colouring) option to mark the most important things in a document (3.66) and retelling something they have just read/seen/heard (3.37) appeared to be of most frequent use, while making mind maps (1.84) and recording oneself reading/saying something and then listening to the recording many times (1.88) were chosen least frequently.

Most frequently reported metacognitive strategies included collecting the addresses of interesting websites (3.65), organising materials in files (3.38) and using criteria to evaluate and choose appropriate websites (3.35). The least frequently used, on the other hand, were writing a blog (1.24) and using a recording option to evaluate one's speaking/pronunciation/reading aloud (1.90).

As for social strategies, contacting friends via email (16.8\%), using an e-encyclopaedia to learn about other people's culture (14\%) were most popular, as opposed to taking part in collaborative projects (65\%) and L2 chats (25\%).

Last but not least, the students stated that when they need a break while learning, they listen to their favourite song (61.5\% always true), they watch a humorous video ( $28 \%$ usually true), and contact their friends ( $21 \%$ usually true). In general, the scope of affective strategies use was considerable and apart from the first strategy there was no clear tendency as for the increased frequency of particular strategies use. 


\section{Inferential Statistics}

The first step in the statistical analysis was verification of normal distribution of scores in particular learning strategy indices. All strategy indices, apart from Affective Strategies Index (ASI), show normal distribution.

Verifying scale reliability was an important step in the presented study, as it meant to investigate to what extent the selection and/or reformulation of strategies was appropriate. The analysis showed that Cronbach's a was relatively high for items of particular strategy scales, with similar values of items if deleted. Almost all inter-item correlations were positive in all the scales apart from the Affective Strategies Scale. This group of strategies had much lower (both positive and negative) correlations for its items, and the overall Affective Strategies scale showed a much lower reliability.

Table 1. Scale reliability statistics for particular groups of strategies.

\begin{tabular}{lccc}
\hline & \multicolumn{3}{c}{ Reliability statistics } \\
\cline { 2 - 4 } & $\begin{array}{c}\text { Cronbach's } \\
\text { Alpha }\end{array}$ & $\begin{array}{c}\text { Cronbach's Alpha based } \\
\text { on standardized items }\end{array}$ & N of Items \\
\hline Learning strategies scale & .791 & .788 & 16 \\
\hline Memorising strategies scale & .784 & .760 & 11 \\
\hline Compensation strategies scale & .681 & .702 & 9 \\
\hline Metacognitive strategies scale & .771 & .758 & 11 \\
\hline Social strategies scale & .776 & .759 & 8 \\
\hline Affective strategies scale & .544 & .550 & 8 \\
\hline
\end{tabular}

The strategies indices showed statistically significant positive relationships for all the pairs (cf., Table 2 below) apart from the Affective Strategies-Compensation Strategies pair. This seems to indicate the fact that the strategies from these two groups are not as widely used together as is the case with some other strategies.

As indicated by the chi-square for independence test, the only factor that did not have a statistical significance on strategy recognition by the participants was age ( $\mathrm{p} \geq 0.05)$. As indicated in Table 3 , the other categorical variables (type of higher education institution, year of studies, teaching experience, learning training wish and traditional strategy training) had a statistically significant effect on the awareness of strategies by the participants, yet to a different degree. Out of these factors, it is quite evident that explicit strategy instruction results in the awareness of strategy use (phi coefficient=.550), while the greater desire to participate in strategy training is coupled with lower strategy recognition (phi coefficient $=-.214)$. 


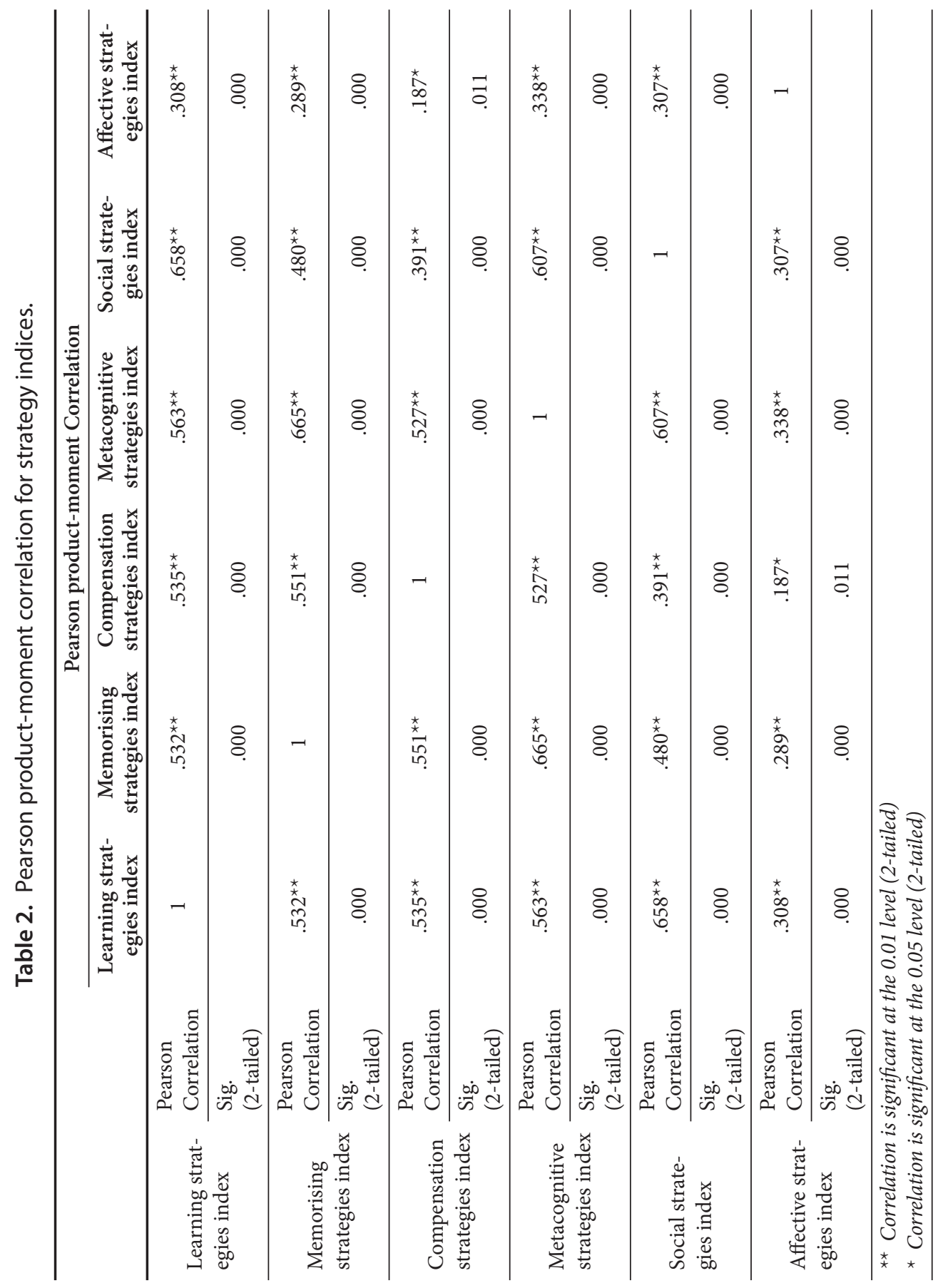


Table 3. Chi-square for independence test for effect on strategy recognition.

\begin{tabular}{lccc}
\hline & \multicolumn{3}{c}{ Strategy recognition } \\
\cline { 2 - 4 } & Phi coefficient & Significance level & N of Items \\
\hline Age & .040 & .860 & 187 \\
\hline Higher education institution & .385 & .000 & 187 \\
\hline Year of studies & .304 & .000 & 187 \\
\hline Teaching experience & .259 & .000 & 187 \\
\hline Learning training wish & -.214 & .004 & 187 \\
\hline Traditional strategy training & .550 & .000 & 187 \\
\hline
\end{tabular}

\section{Discussion}

The data elaborated in the research allowed for the discussion on three different aspects: implications for teaching, the reliability of the SI-LLE instrument and suggestions for further research.

To start with, the students who have experienced strategy training are the ones who are able to recognize a wider range of strategies. Those, however, who did not express the wish to go through strategy training reveal a lack of knowledge over what learning strategies are. This seems to prove that students need guidance and training to become aware of possibilities that could be used to enhance the learning process.

Furthermore, student teachers can boast a greater variety of strategies in CALL and appear to be more conscious learners as well. Teaching experience, thus, contributes to stimulating the need to scrutinize various solutions.

Transferring some strategies into the process may therefore be one of the solutions to inspire students into reflection on their own learning. It may prove beneficial to apply tasks which engage students not only in language work, but also prompt them to analyze the particular steps that need to be taken. Additionally, as Hubbard (2004) suggests, educators ought to follow 'a cyclic approach' to learner training to allow trainees ample time to create new ideas and remind them of points they may easily forget over time.

The research also brought up the need to re-conceptualise the SI-LLE instrument. This concerns the group of Affective Strategies mainly due to its low rank in reliability tests, and reflection on statement wording is needed here. It seems the section of the SI-LLE pertaining to Affective Strategies is not fully relevant to the 
Polish context, mainly due to the fact that the Polish education system places little emphasis on catering for the emotional sphere of the learner.

The results of the presented study clearly show a need for wide-scale investigation into learning strategy inventories adapted to the present reality of digital learning environments. The SI-LLE instrument is such an attempt as, to a great extent apart from the Affective Strategies section, it proved to be highly relevant to the investigated context. The application of randomisation of participants within purposively selected sampling clusters helped to increase the generalisability of results.

Moreover, the authors are well aware of the major limitations of correlational studies, namely, the very existence of correlation only shows the instance of co-existence, but there is no implication of a cause-and-effect relationship. Thus, further research into the mutual relationships between particular strategies is recommended.

\section{Conclusions}

Improving the effectiveness of the learning process should be the ultimate aim of instruction in any setting. Nowadays, only a little part of learning is actually done in class, with most of knowledge and skills acquired by learners in various personal learning settings outside the classroom. It becomes, thus, of paramount importance to make learners aware of the particular steps and operations they can consciously apply in order to maximise their chances of learning success.

The awareness of how contemporary 'digital native' students (Prensky, 2001, 2004) learn is a key to organizing successful teaching. With the application of the SI-LLE as a diagnostic tool, instructors can more effectively tailor strategy instruction to the needs of their learners. Being more aware of their learning strengths and possible ways of coping with learning weaknesses, students can become better teachers in the future.

\section{References}

Brown, H.D. (1987) The principles of language teaching and learning. Eaglewood Cliffs, NJ: Prentice Hall.

Bull, S. (1997) Promoting effective learning strategy use in CALL. Computer Assisted Language Learning, 10, 3-39. DOI: 10.1080/0958822970100102. 
Burzyńska, K. (2012). While curiosity killed the cat... wasn't it satisfaction that brought it back? - EAPQuest as a modified version of Webquest in the context of university teaching. Teaching English with Technology, 12 (4). Retrieved 7/01/2015, from URL http://tewtjournal.org/issues/past-issue-2012/past-issue-2012-issue-4/

Burzyńska, K., \& Krajka, J. (2014). Developing university students' learning strategies in CALL environments. In A. Turula \& B. Mikołajewska (Eds.), Insights into technology enhanced language pedagogy (pp. 193-203). Frankfurt: Peter Lang.

Chen, L., Zhang, R. \& Liu, C. (2013) Listening strategy use and influential factors in Webbased computer assisted language learning. Journal of Computer-Assisted Learning, Early view article. DOI: 10.1111/jcal.12041.

Cohen, L., Manion, L., \& Morrison, K. (2011) Research methods in education. London: Routledge.

$\mathrm{Gu}$, P. (2003). Vocabulary learning in a second language: person, task, context and strategies. TESL-EJ, 7 (2). Retrieved 3/11/2013, from URL http://tesl-ej.org/ej26/a4.html.

Hubbard, P. (2004). Learner training for effective use of CALL. In S. Fotos \& C. Browne (Eds.), New perspectives in CALL for second language classrooms (pp. 45-67). Mahwah: Lawrence Erlbaum.

Li, J. (2009). The evolution of vocabulary learning strategies in a computer-mediated reading environment. CALICO Journal, 27 (1), 118-146. DOI: http://dx.doi.org/10.11139/ cj.27.1.118-146.

Nassaji, H. (2003). L2 vocabulary learning from context: strategies, knowledge sources, and their relationship with success in L2 lexical inferencing. TESOL Quarterly, 37 (4), 645-670. DOI: $10.2307 / 3588216$.

O’Malley, J.M., \& Chamot, A. U. (1990). Learning strategies in Second Language Acquisition. Cambridge: Cambridge University Press.

Oxford, R. (1990). Learning strategies: what every teacher should know. New York: Newbury House/Harper \& Row.

Prensky, M. (2001). Digital natives, digital immigrants. On the Horizon, 9 (5), October 2001. Retrieved 3/11/2013, from http://www.marcprensky.com/writing/Prensky\%20 -\%20Digital\%20Natives,\%20Digital\%20Immigrants\%20-\%20Part1.pdf.

Prensky, M. (2004). The emerging online life of the digital native. Retrieved 3/11/2013, from http://www.marcprensky.com/writing/Prensky-The_Emerging_Online_Life_of_ the_Digital_Native-03.pdf.

Ranalli, J. (2009). Prospects for developing L2 students' effective use of vocabulary learning-strategies via web-based training. CALICO Journal, 27 (1), 161-186. DOI: http:// dx.doi.org/10.11139/cj.27.1.161-186.

Schmitt, N. (1997). Vocabulary learning strategies. In R. Carter \& M. McCarthy (eds.), Vocabulary and language teaching (pp. 198-218). New York: Longman.

Wenden, A. (1983). Literature review: the process of intervention. Language Learning, 33, 103-21. DOI: 10.1111/j.1467-1770.1983.tb00988.x.

Advised by Ferit Kilickaya, Ph.D., Mehmet Aksoy University, Ankara, Turkey 